\author{
Е. Д. Бутовский \\ Одесская национальная академия пищевых технологий, ул. Канатная, 112, г. Одесса, 65039, Украина \\ $\triangle$ e-mail: ariesoon@gmail.com, ORCID: http://orcid.org/0000-0002-5260-4952
}

\title{
УСТРОЙСТВО ДЛЯ ПОДАЧИ ЖИДКОГО ХЛАДАГЕНТА В ЭЖЕКТОРНЫЙ ТЕПЛООБМЕННИК
}

В состав дымовых газов в зависимости от вида топлива или режима горения включают множество различных соединений. Эффективным методом очистки дымовых газов является ввод в поток газов различных химических веществ. Конденсачионный эжекторный фильтр предназначен для конденсации канцерогенных смол, которые образуются при розжиге котлов на смеси низкокачественных угольных топлив, а также при переходных режимах.

Ключевые слова: Дымовые газы; Поличиклические ароматические углеводороды; каниерогены, Эжекторный фильтр; Газовый поршень.

\section{С. Д. Бутовський, В. О. Когут, В. М. Бушманов, М. Г. Хмельнюк}

Одеська національна академія харчових технологій, вул. Канатна, 112, г. Одеса, 65039, Україна

\section{ПРИСТРІЙ ДЛЯ ПОДАЧІ РІДКОГО ХЛАДАГЕНТУ В ЕЖЕКТОРНИЙ ТЕПЛООБМІННИК}

До складу димових газів залежно від виду палива або режиму горіння включають безліч різних сполук. Ефективним методом очищення димових газів є введення в потік газів різних хімічних речовин. Конденсаиійний ежекторний фільтр призначений для конденсації канцерогенних смол, які утворюються при запалюванні котлів на суміші низькоякісних вугільних палив, а також, при перехідних режимах.

Ключові слова: Димові гази; Поліщиклічні ароматичні вуглеводні; Канцерогени; Ежекторний фільтр; Газовий поршень.

This work is licensed under the Creative Commons Attribution International License (CC BY). http://creativecommons.org/licenses/by/4.0/

\section{І. ВВЕДЕНИЕ}

Экономия энергетических ресурсов различными способами не всегда приводит к ожидаемому результату. Если рассматривать нетрадиционные методы производства энергии, то, в целом, они безопасны, за исключением некоторых. Другое дело - совершенствование традиционных методов (смешение продуктов горения, производство искусственных топлив) приводит к повышенной опасности для окружающей среды обитания, так и здоровья человека. Существующие методы очистки и защиты окружающей среды не всегда эффективны, а при стечении обстоятельств не справляются с поставленной задачей

\section{ІІ. АКТУАЛЬНОСТЬ ПРОБЛЕМЫ}

В состав дымовых газов в зависимости от вида топлива или режима горения включают тысячи различных соединений. Наибольшую угрозу для здоро- вья человека и других живых организмов являются вещества, вызывающие онкологические заболевания. Канцерогенные вещества представляются в дымовых газах полициклическими ароматическими углеводородами. К числу наиболее канцерогенно активных относится бензапирен. Также в составе дымовых газов из канцерогенных веществ в наибольшем количестве присутствуют бензантрацен, керонен, фенантрен и пирен. Наибольший выход канцерогенов наблюдается при стартовых и переходных режимах. При использовании в котельных установках в качестве топлива газа и углей высокого качества, прогнозирование состава дымовых газов не составляло труда. Однако, в виду определенных экономических условий в Украине, планируется массовый переход котельных на использование смесей из различных сортов углей и мазутов низкого качества. В таком случае расчет состава дымовых газов становится проблематичным. К тому же известные системы очистки дымовых газов рассчитаны на дымовые газы, образующиеся при 
сжигании определенного топлива. Нестабильный состав смесей топлив также дает на выходе различные составы дымовых газов. В момент старта котла количество выбросов возрастает на 90\%. В составе сбрасываемых дымовых газов находятся не только такие вредные вещества как окись азота, окись углерода, окись серы, но также смолы, бензапирены, бензолы, формальдегиды, которые способствуют развитию раковых клеток [4].

\section{ІІІ. ФИЛЬТР КАНЦЕРОГЕННЫХ ГАЗОВ}

В связи с вышесказанным возникает необходимость создания эффективных методов очистки дымовых газов от канцерогенных веществ, находящихся в них, на этапах розжига и сменных режимов. Хорошим решением может стать показанный ниже эжекторный фильтр (рисунок 1).

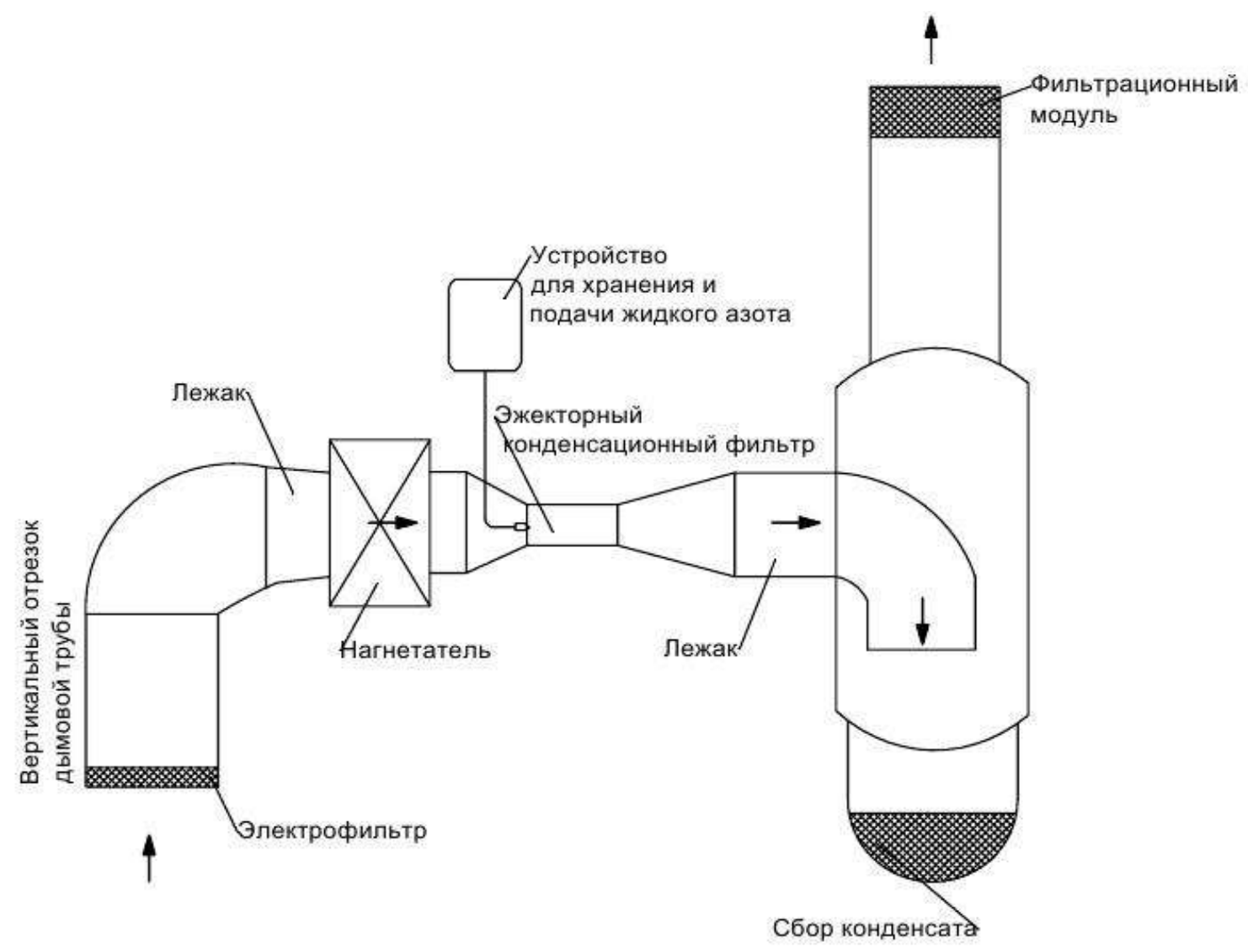

Рисунок 1 - Эжекторный фильтр

Этот фильтр обеспечивает высокую эффективность очистки за счет эффекта охлаждения основного потока, и сбора конденсата канцерогенных веществ во время розжига установки [2-3].

\section{IV УСТРОЙСТВА ДЛЯ ПОДАЧИ ХЛАДАГЕН- ТОВ В ЭЖЕКТОРНЫЙ ТЕПЛООБМЕННИК}

Особой сложностью является подача в форсунку эжекторного теплообменника хладагента для контактного охлаждения потока [1]. Ниже рассмотрены различные типы устройств. Одной из задач является ускорение хладагента из форсунки до скорости основного потока дымовых газов. Это очень важно, так как использующие хладагенты обладают низкими температурами кипения. Устройства подачи хлада- гента тщательно изолируются для уменьшения теплопритоков от окружающей среды, и обеспечивается забор испарившегося пара. На рисунке 3 изображен расчетный расход углекислоты при работе устройства для трех температурных зон.

Данное устройство состоит из цилиндра высокого давления, внутри которого свободно перемещается газовый поршень. Залив углекислоты осуществляется через регулирующее устройство подачи жидкости и забора паров. Из рабочего цилиндра жидкая кислота поступает к форсунке эжектора-теплообменника через охладитель-разделитель, где за счет балластного пара происходит охлаждение жидкости, что не доводит до вскипания в трубопроводе подачи. Газовый поршень обеспечивает равномерную подачу жидкой углекислоты к форсунке при помощи уравнительного трубопровода. 


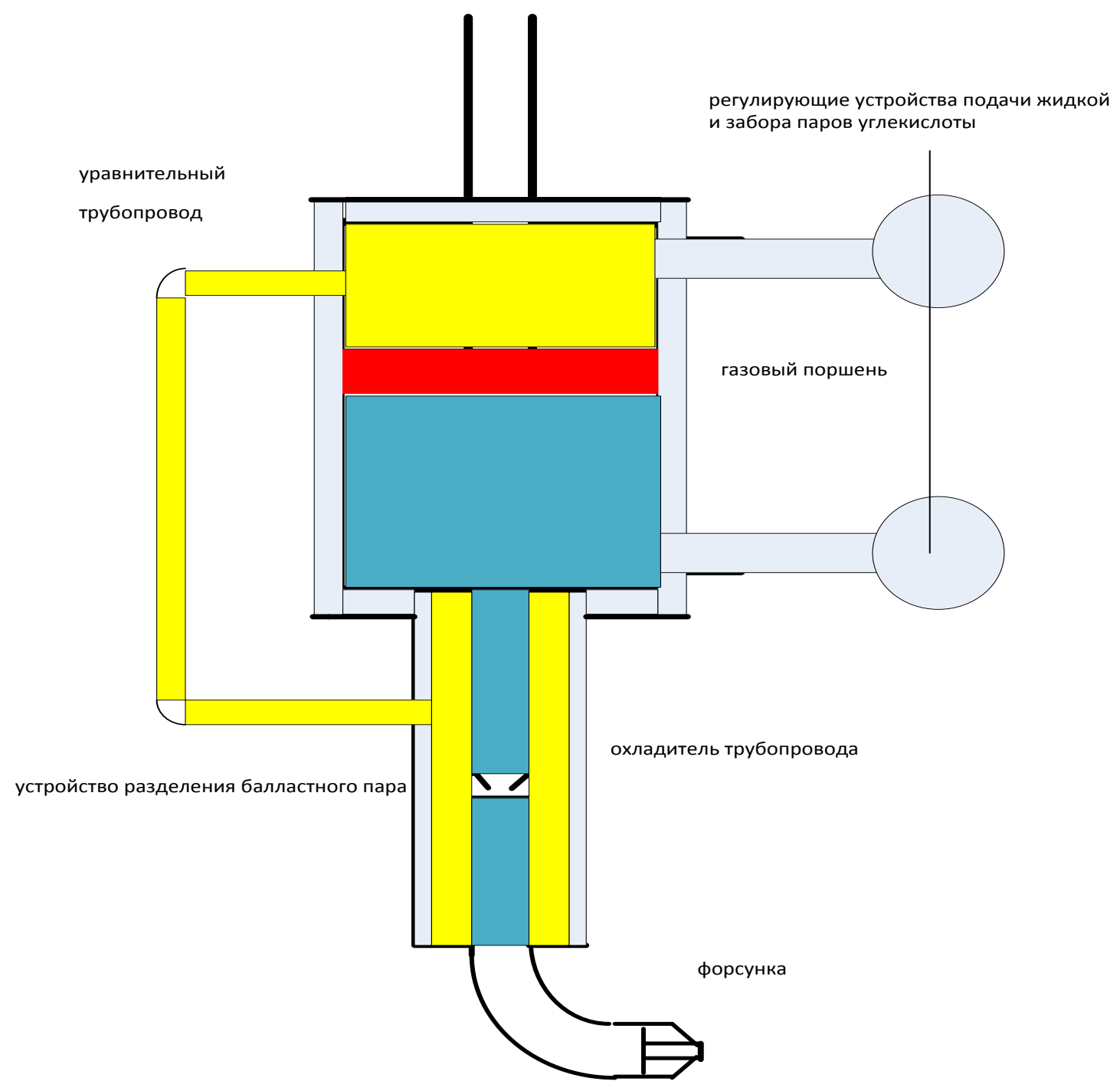

Рисунок 2 - Устройство для подачи углекислоты в эжектор-теплообменник.

Таблица 1 - Расчетное количество жидкой углекислоты для конденсации канцерогенов.

\begin{tabular}{|c|c|c|c|c|c|c|}
\hline \multicolumn{7}{|c|}{ Количество впрыскиваемой углекислоты, отнесенной к одному килограмму дымовых газов } \\
\hline \multirow{2}{*}{$\begin{array}{c}\text { Температура конечной точки охла- } \\
\text { ждения, }{ }^{0} \mathrm{C}\end{array}$} & \multicolumn{2}{|c|}{$\begin{array}{c}\text { Зона начала го- } \\
\text { рения } \\
\text { Т мах. }{ }^{\circ} \mathrm{C}\end{array}$} & \multicolumn{2}{|c|}{$\begin{array}{c}\text { Зона стабилизации } \\
\text { горения } \\
\text { T мах. }{ }^{\circ} \mathrm{C}\end{array}$} & \multicolumn{2}{|c|}{$\begin{array}{c}\text { Зона предельной темпе- } \\
\text { ратуры } \\
\text { Т мах. }{ }^{\circ} \mathrm{C}\end{array}$} \\
\hline & $\mathrm{T}_{\text {зоны }}{ }^{0} \mathrm{C}$ & $\mathrm{G}_{\text {ук }}$ кг. & $\mathrm{T}_{\text {зоны }}{ }^{0} \mathrm{C}$ & $\mathrm{G}_{\text {ук }}$ кг. & $\mathrm{T}_{\text {зоны }}{ }^{0} \mathrm{C}$ & $\mathrm{G}_{\text {ук }}$ кг. \\
\hline 25 & 240 & 1,996 & 390 & 3,385 & 590 & 5,23 \\
\hline 30 & 240 & 1,95 & 390 & 3,39 & 590 & 5,19 \\
\hline 35 & 240 & 1,905 & 390 & 3,29 & 590 & 5,14 \\
\hline 40 & 240 & 1,859 & 390 & 3,24 & 590 & 5,1 \\
\hline 45 & 240 & 1,814 & 390 & 3,2 & 590 & 5,05 \\
\hline
\end{tabular}




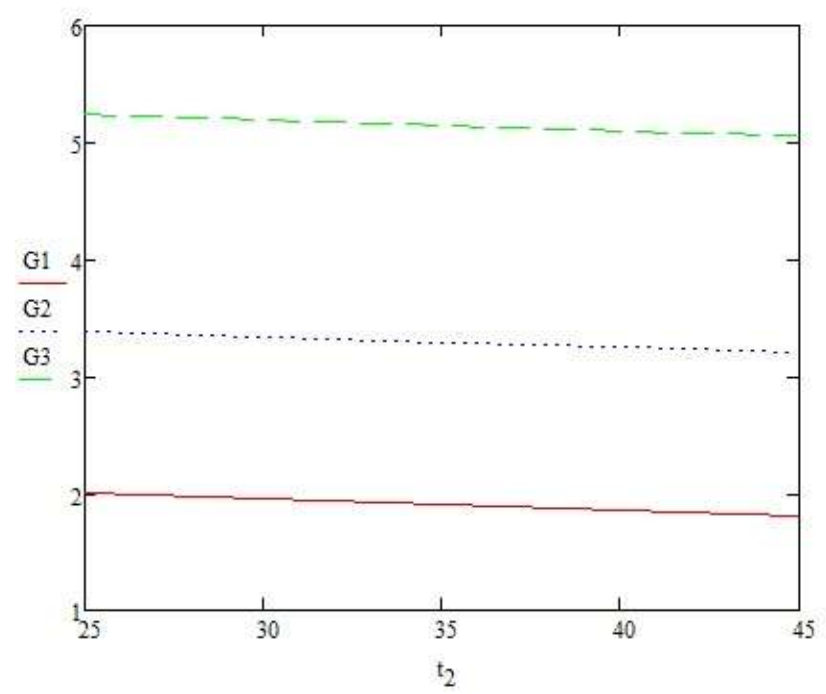

Рисунок 3 - График расхода углекислоты при очистке дымовых газов в фильтре эжектора.

На рисунках 4 и 5 изображены два способа подачи жидкого азота в эжекторный теплообменник. От устройства подачи углекислоты отличаются несколько более простым устройством. Плавность подачи регулируется в одном случае вручную, в другом - за счет терморегулирующего вентиля, который обеспечивает некоторую степень автоматизации процесса подачи хладагента. Изоляция трубопровода подачи может обеспечиваться за счет вакуумной теплоизоляции, или с помощью переливного устройства, охлаждающего поток подачи.

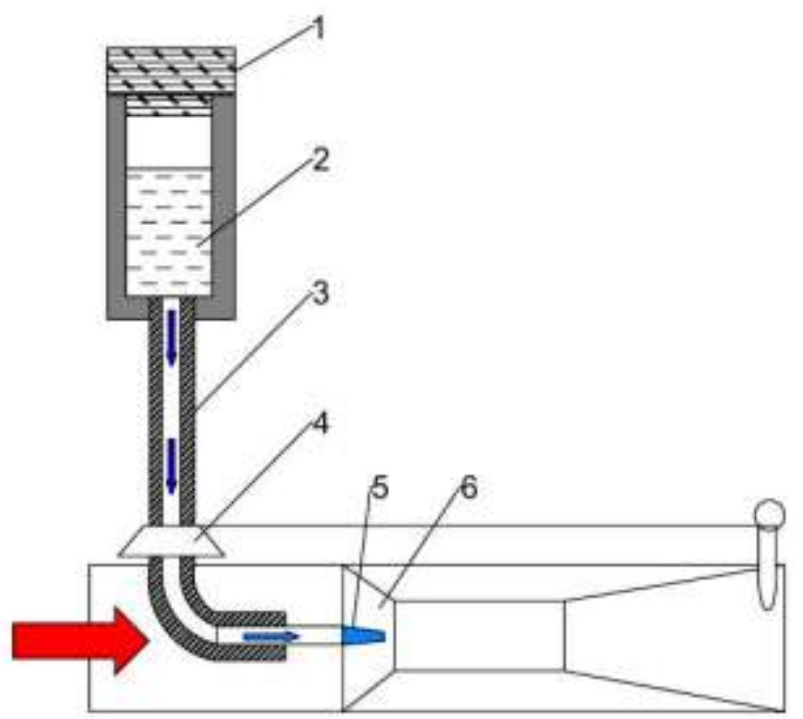

1 - крышка; 2 - изолированная емкость с жидким азотом; 3 - высоковакуумный криогенный трубопровод; 4 - запорно-регулирующее устройство; 5 - форсунка; 6 - эжектор-теплообменник

Рисунок 4 - Устройство экспериментальной подачи жидкого азота в эжектор-теплообменник.

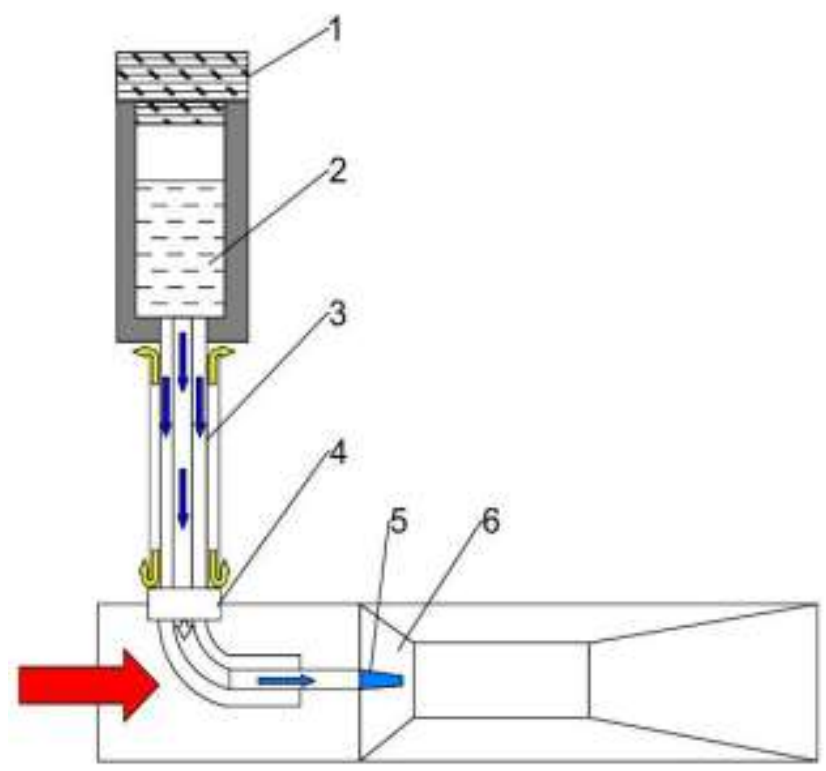

1 - крышка; 2 - изолированная емкость с жидким азотом; 3 - криогенное переливное устройство; 4 - запорно-регулирующее устройство; 5 - форсунка; 6 эжектор-теплообменник

Рисунок 5 - Устройство экспериментальной подачи жидкого азота в эжектор-теплообменник

На рисунке 6 изображено расчетное количество азота, необходимое для охлаждения дымовых газов для определенного состояния для нескольких температурных уровней. Из графика видно, что необходимое количество азота для охлаждения меньше, чем для углекислоты [5]. Это объясняется теплофизическими свойствами жидкого азота.

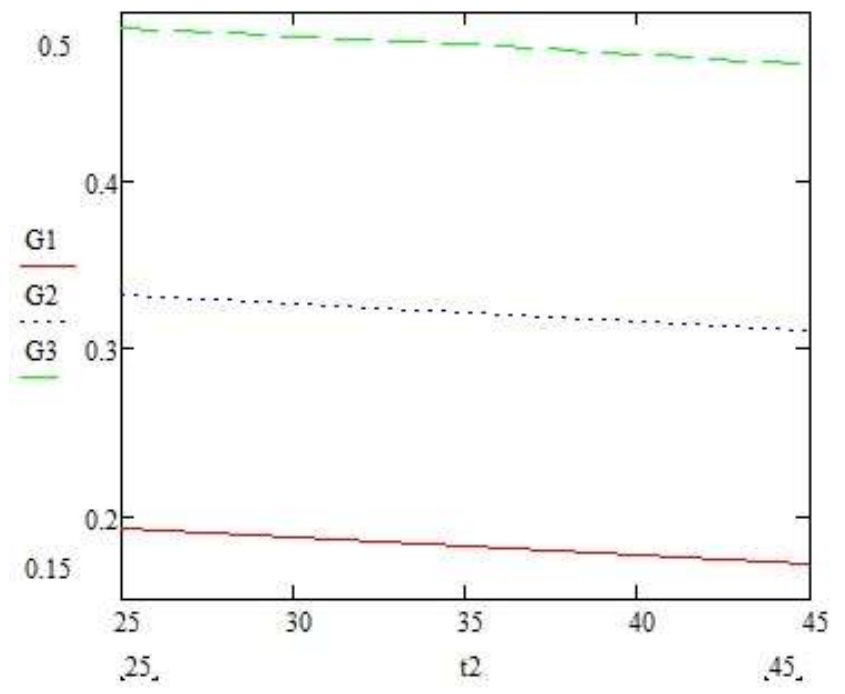

Рисунок 6 - График расхода жидкого азота при очистке дымовых газов в фильтре эжектора. 
Таблица 2 - Расчетное количество жидкого азота для охлаждения дымовых газов

\begin{tabular}{|c|c|c|c|c|c|c|}
\hline \multirow{3}{*}{$\begin{array}{l}\text { Температура конечной } \\
\text { точки охлаждения, 0С }\end{array}$} & уть жидко & азота, отн & енного к о & у килограм & дымовых & \\
\hline & \multicolumn{2}{|c|}{$\begin{array}{c}\text { Зона начала горения } \\
\text { T мax. = 0С }\end{array}$} & \multicolumn{2}{|c|}{$\begin{array}{c}\text { Зона стабилизации горе- } \\
\text { ния } \\
\text { T мах. }=0 \mathrm{C}\end{array}$} & \multicolumn{2}{|c|}{$\begin{array}{c}\text { Зона предельной } \\
\text { температуры } \\
\text { Т мах. = 0С }\end{array}$} \\
\hline & $\mathrm{T}_{\text {зоны }}{ }^{0} \mathrm{C}$ & $\mathrm{G}_{\text {азота }}$ Кг. & $\mathrm{T}_{\text {зоны }}{ }^{\circ} \mathrm{C}$ & $\mathrm{G}_{\text {азота }}$ Кг. & $\mathrm{T}_{\text {зоны }}{ }^{0} \mathrm{C}$ & $\mathrm{G}_{\text {азота }}$ кг. \\
\hline 25 & 240 & 0,193 & 390 & 0,332 & 590 & 0,491 \\
\hline 30 & 240 & 0,187 & 390 & 0,326 & 590 & 0,486 \\
\hline 35 & 240 & 0,182 & 390 & 0,321 & 590 & 0,481 \\
\hline 40 & 240 & 0,177 & 390 & 0,316 & 590 & 0,475 \\
\hline 45 & 240 & 0,171 & 390 & 0,31 & 590 & 0,47 \\
\hline
\end{tabular}

На рисунке 7 представлена модель протекания жидкости через фильтр эжектор. Модель создана с помощью специального программного обеспечения. На данном рисунке видны процессы ускорения в сужающемся участке, а затем торможение на участке с расширением, где происходят активные завихрения и смешивание потоков. На этом же участке, после смешивания потоков, происходит конденсация канце- рогенных смол. В данной модели смоделированы эффекты, наблюдаемые в потоках без впрыска. Как видно из модели даже без впрыска может наблюдаться частичное выпадение в осадки канцерогенов. При применении в эжекторе впрыска и смешивания потоков, ожидаемый эффект конденсации канцерогенов возрастает в несколько раз, что увеличивает степень очистки дымовых газов.

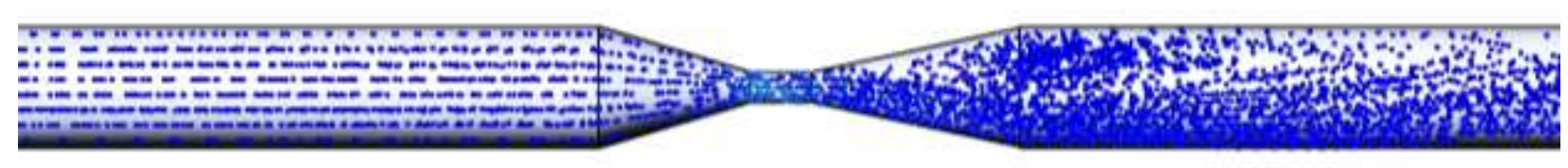

Рисунок 7 - Моделирование потока в эжекторе

\section{ВЫВОДЫ}

Теплообменный эжекторный фильтр предназначен для охлаждения дымовых газов во время розжига топки и при достижении предельной температуры горения отключается. Основной задачей фильтра является извлечение из основного потока канцерогенных веществ с температурами кипения $\left(80-400{ }^{\circ} \mathrm{C}\right)$ из зоны начала горения и зоны стабилизации горения. Собранные канцерогенные вещества утилизируются. Метод очистки дымовых газов от канцерогенных веществ позволяет уменьшить вредные выбросы до $99 \%$.

\section{ЛИТЕРАТУРА}

1. Когут В. Е. Применение эжекторных теплообменников в различных областях промышленности // В. Е. Когут, Е. Д. Бутовский / Восточно-Европейский журнал передовых технологий. - Харьков - 2014 Том 5, вып. 1 (71) - С. 51-58.
2. Когут В. Е. Эжекционный фильтр для конденсации канцерогенов в составе дымовых газов // Когут В. Е., Бушманов В. М., Бутовский Е. Д., Хмельнюк М. Г. / International scientific conference "High technologies. Business. Society 2016" — №5 (191) - 16.03.2016

3. Очистка вредных выбросов дымовых газов котельных [Электронный ресурс, название с экрана]. Режим доступа: http://ecoalliance.com.ua/ bbloteka/stattpo-povtryu/ochistka-vrednyix-vyibrosov-dyimovyixgazov-kotelnyix.

4. Когут В. Е. Защита окружающей среды от канцерогенных смол при розжиге отопительных систем // В. Е. Когут, Е. Д. Бутовский / Холодильная техника и технология. - Одесса - 2014 - Том 51, вып. 4 - С. 45 52. DOI:10.15673/0453-8307.4/2015.39288

5. Жихарсва Н. В. Особливості розрахунку теплопипливів в приміщення при кондиціюванні повітря // Н.В.Жихарєва/ Холодильна техніка і технологія 2015. -Том.51 №6. -C. $17-20$.

DOI: $10.15673 / 0453-8307.6 / 2015.44778$

Отримана в редакції 14.06.2016, прийнята до друку 01.07.2016 


\section{Butovskyi ${ }^{凶}$, V. Kogut, V. Bushmanov, M. Khmelniuk}

Odessa National Academy of Food Technologies, Kanatnaya str., 112, Odessa, 65039, Ukraine

$\bowtie$ e-mail: ariesoon@gmail.com, ORCID: http://orcid.org/0000-0002-5260-4952

\section{THE DEVICE FOR SUPPLYING LIQUID REFRIGERANT INTO THE EJECTOR HEAT EXCHANGER}

In the modern industry it is necessary to bolster ecological security of manufactures and do not suppose environmental discharges of hazardous substances. The tense ecological situation in different areas, especially in industrial, defined an urgency of the yield operation. For thin scrubbing action of flue gases it is offered to use the ejector condensation screen of an open-type heat exchanger which is based on the method of flue gases flow cooling below dew-point temperature. In composition of flue gases depending on a fuel or a combustion regime powered up flock of different joints. An efficient purification method of flue gases lies in addition of different chemicals into the gases flow. The condensation ejector filter is intended for condensation of carcinogenic tars which are formed during boiler ignition on a mixture of low-quality coal fuels, as well as at transient modes.

Keywords: Flue Gases; Polycyclic Aromatic Hydrocarbons; Carcinogenic; Ejector Filter; Gas Piston.

\section{REFERENCES}

1. Kogut, V. E. Butovskyi, I. D. (2014). Use of the ejector heat exchangers in different areas of industry. East European Journal of Enterprise Technologies. Vol. 5, iss. 1(71), 51-58. DOI: 10.15587/1729-4061.2014.28640.

2. Kogut V., Bushmanov V., Butovskyi I., Khmelniuk M. (2016). Condensation ejector filter is intended for condensation of carcinogenic in flue gases. Procc. Of International scientific conference "High technologies. Business. Society 2016", 16 March 2016, No.5 (191).

3. Ochistka vrednykh vybrosov dymovykh gazov kotelen [Electronic source]. URL: http://ecoalliance.com.ua/ bbloteka/statt-po-povtryu/ochistka-vrednyix-vyibrosovdyimovyix-gazov-kotelnyix (in Russian).

4. Kogut, V. E., Butovskyi, I. D., Bushmanov, V. M., Khmelniuk, M. G. (2015). Environmental protection against carcinogens resin at ignition of heating systems $R e$ frigeration engineering and technology, 51(4), 45-52 (in Russian) DOI:10.15673/0453-8307.4/2015.39288

5. Zhikhareva N. V. (2015). Calculation features of heat gain in an air conditioning room. Refrigeration engineering and technology, 51(6), 17-20 (in Ukrainian).

DOI: $10.15673 / 0453-8307.6 / 2015.44778$

Received 14 June 2016 Approved 01 July 2016 Available in Internet 31 August 2016 